\title{
Article \\ Uncertainties in Atomic Data for Modeling Astrophysical Charge Exchange Plasmas
}

\author{
Liyi Gu ${ }^{1,2, *(\mathbb{D}, \text { Chintan Shah }}{ }^{3,4,5}$ and Ruitian Zhang ${ }^{6,7}(\mathbb{C}$ \\ 1 SRON Netherlands Institute for Space Research, Niels Bohrweg 4, 2333 CA Leiden, The Netherlands \\ 2 RIKEN High Energy Astrophysics Laboratory, 2-1 Hirosawa, Wako 351-0198, Saitama, Japan \\ 3 NASA Goddard Space Flight Center, 8800 Greenbelt Rd., Greenbelt, MD 20771, USA; chintan@mpi-hd.mpg.de \\ 4 Max-Planck-Institut für Kernphysik, Saupfercheckweg 1, D-69117 Heidelberg, Germany \\ 5 Lawrence Livermore National Laboratory, 7000 East Avenue, Livermore, CA 94550, USA \\ 6 Institute of Modern Physics, Chinese Academy of Sciences, Lanzhou 730000, China; zhangrt@impcas.ac.cn \\ 7 University of Chinese Academy of Sciences, Beijing 100049, China \\ * Correspondence: l.gu@sron.nl
}

check for

updates

Citation: Gu, L.; Shah, C.; Zhang, R. Uncertainties in Atomic Data for Modeling Astrophysical Charge Exchange Plasmas. Sensors 2022, 22, 752. https://doi.org/10.3390/ s22030752

Academic Editor: Bruno Miguel Soares Gonçalves

Received: 10 December 2021 Accepted: 14 January 2022 Published: 19 January 2022

Publisher's Note: MDPI stays neutral with regard to jurisdictional claims in published maps and institutional affiliations.

Copyright: (C) 2022 by the authors Licensee MDPI, Basel, Switzerland. This article is an open access article distributed under the terms and conditions of the Creative Commons Attribution (CC BY) license (https:// creativecommons.org/licenses/by/ $4.0 /)$.

\begin{abstract}
Relevant uncertainties of theoretical atomic data are vital to determining the accuracy of plasma diagnostics in a number of areas, including, in particular, the astrophysical study. We present a new calculation of the uncertainties on the present theoretical ion-impact charge exchange atomic data and X-ray spectra, based on a set of comparisons with the existing laboratory data obtained in historical merged-beam, cold-target recoil-ion momentum spectroscopy, and electron beam ion traps experiments. The average systematic uncertainties are found to be $35-88 \%$ on the total cross sections, and $57-75 \%$ on the characteristic line ratios. The model deviation increases as the collision energy decreases. The errors on total cross sections further induce a significant uncertainty to the calculation of ionization balance for low-temperature collisional plasmas. Substantial improvements of the atomic database and dedicated laboratory measurements are needed to obtain the current models, ready for the $\mathrm{X}$-ray spectra from the next $\mathrm{X}$-ray spectroscopic mission.
\end{abstract}

Keywords: charge exchange; $\mathrm{X}$-ray astrophysics; atomic data; plasma diagnostics

\section{Introduction}

Charge exchange plasma can be found in a broad range of astrophysical environments, including, in particular, the interfaces where the solar wind ions interact with neutrals in comets and planetary atmospheres [1-4], but potentially also in supernova remnants [5,6], star-forming galaxies [7,8], active galactic nuclei [9], and clusters of galaxies [10,11]. The modeling of the X-ray spectrum of charge exchange has become possible recently thanks to the efforts of Smith et al. [12] and Gu et al. [13]. These models are crucial to interpreting the observations, as well as to understanding the physical sources that power the plasma.

There is an increasing demand from the astronomical community that the plasma model should provide an estimate of the systematic uncertainties for the atomic data used. This is triggered by the accumulating evidence that the uncertainties from the atomic data, which are not accounted for at present, are as significant as the typical errors from instrumental calibration (see [14] for a recent example). So far, there is no systematic estimate of the uncertainties of the existing charge exchange models, making it difficult to assess the accuracy of the scientific results obtained with these models.

Most of the charge exchange reaction rates in existing models are obtained in theoretical calculations, with only a few laboratory benchmarks performed by several groups with various experimental methods (see, e.g., cross-beam/merged-beam neutral setups: [15-17]; tokamak and laser-produced plasmas: [18-20]; cold-target recoil-ion momentum spectroscopy (COLTRIM): [21-25]; electron beam ion trap (EBIT): [26-32]). A recent comparison using the data from the EBIT measurements [33] showed that the model and the laboratory spectra differ significantly in both line energies and strengths, for the L-shell charge 
exchange between nickel ions and neutral particles. Another recent example is that the COLTRIMS measurement by $\mathrm{Xu}$ et al. [34] showed that the model calculations might differ from the measurements by $20-50 \%$ for the state-selective cross sections of $\mathrm{Ne}^{8+}$ and $\mathrm{Ne}^{9+}$ charge exchange. In this work, we compile a sample of existing laboratory measurements on charge exchange total cross sections, and state-selective cross sections, as well as characteristic X-ray line ratios, and put forward a systematic assessment of the model accuracy.

This paper is arranged as follows. In Section 2, we describe the sample and the results of the benchmark, and in Section 3, we discuss the potential improvement with future EBIT and COLTRIMS measurements. The benchmark is directly applied to the charge exchange model and atomic data [13] in the SPEX [35] software. Throughout the paper, the errors are given at a $68 \%$ confidence level.

\section{Methods and Results}

\subsection{Total Cross Sections}

First, we compare the SPEX calculations with existing laboratory results for a number of ions on their total cross sections for atomic hydrogen targets. The SPEX atomic data do not constitute one uniform set of theoretical calculations, but a mixture of three different types of approaches: (1) the rates derived with the empirical scaling reported in Gu et al. [13] (G16 hereafter), which was based on a numerical approximation to a collection of historical theoretical and experimental rates; (2) the multi-channel Landau-Zener method (hereafter MCLZ) reported in Mullen et al. [36]. The atomic data generated by MCLZ are also publicly available in the Kronos database (https: / / www.physast.uga.edu/research/ stancil-group / atomic-molecular-databases/kronos, accessed on 1 December 2021); and (3) the recommended values (hereafter RCMD), based on dedicated calculations, including, in most cases, the quantum-mechanical and classical molecular-orbital close-coupling methods, and the atomic-orbital close-coupling method. The G16 approach can calculate, for any ions with a given atomic number and charge, the MCLZ data covering most of the $\mathrm{H}$ - and He- like ions with atomic number up to 30, and the RCMD rates are available for a small set of key ions, e.g., O VII [37], N VII [38], and C VI [39].

All the three datasets are tested when the corresponding theoretical cross sections $\left(\sigma_{\text {theo }}\right)$ and experimental cross sections $\left(\sigma_{\text {exp }}\right.$, see Table 1$)$ are available. Examples are shown in Figure 1 for the C VI and O VII data. For C VI, the three calculations converge at the energy range from $\sim 100 \mathrm{eV} / \mathrm{amu}$ to $4 \times 10^{4} \mathrm{eV} / \mathrm{amu}$, while the MCLZ data do not cover higher energies, and the G16 and RCMD data miss the low energy part. For O VII, the difference between the three calculations becomes more significant than in the case of C VI. The cross section derivatives shown in Figure 1 indicate that the differences in the shapes of the three theoretical calculations become, in general, larger at lower collision energies.

In Figure 2, we plot the distributions of the absolute errors $\sigma_{\exp }-\sigma_{\text {theo }}$ of the theoretical models. The standard deviations of the absolute errors are $1.4 \times 10^{-15} \mathrm{~cm}^{-2}$, $2.0 \times 10^{-15} \mathrm{~cm}^{-2}$, and $1.3 \times 10^{-15} \mathrm{~cm}^{-2}$, for the G16, MCLZ, and RCMD calculations, respectively. As shown in Figure 2b, the absolute errors of G16 become more scattered, and on average larger, at lower collision velocities. The standard deviations of the error distributions are $1.8 \times 10^{-15} \mathrm{~cm}^{-2}$ for $v<600 \mathrm{~km} \mathrm{~s}^{-1}$, and $0.9 \times 10^{-15} \mathrm{~cm}^{-2}$ for $v \geq 600 \mathrm{~km} \mathrm{~s}^{-1}$.

We also summarize the relative deviations $\left(\sigma_{\exp }-\sigma_{\text {theo }}\right) / \sigma_{\text {theo }}$ of the three calculations in Figure 2. The average absolute values of the fractional deviations are $55 \%, 88 \%$, and $35 \%$ for the G16, MCLZ, and RCMD datasets. Similar to G16, the MCLZ calculation also has larger relative errors for low-velocity collisions, while the RCMD calculation shows fairly constant deviations for the velocity range considered. For high-energy collisions of $v>3000 \mathrm{~km} \mathrm{~s}^{-1}$, the three methods show reasonable agreement with the laboratory results within uncertainties $<50 \%$. 

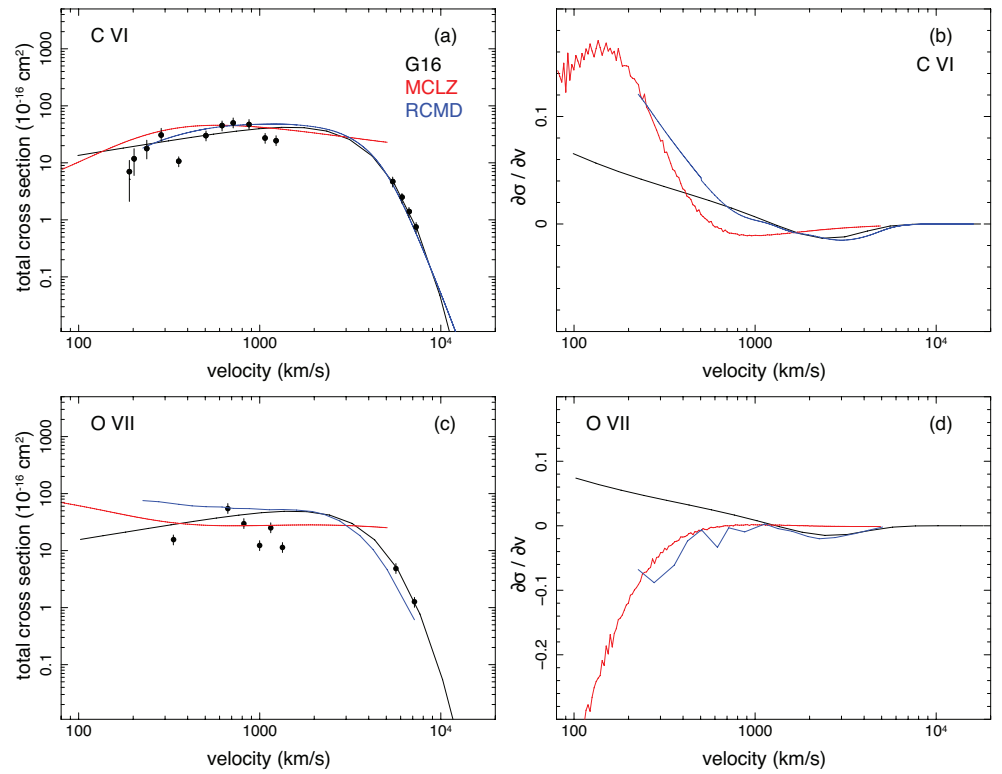

Figure 1. Total cross sections as a function of collision velocity and the cross section derivatives with respect to the velocity for $\mathrm{C}^{6+}(\mathbf{a}, \mathbf{b})$ and $\mathrm{O}^{7+}(\mathbf{c}, \mathbf{d})$ ions interacting with hydrogen atoms, resulting in $\mathrm{C}$ VI and O VIII ions. The data points are experimental results from Goffe et al. [40], Phaneuf et al. [41], Panov et al. [42], and Meyer et al. [43]. Approximate errors of 15\% [43] are shown, except for the low energy $\left(<500 \mathrm{~km} \mathrm{~s}^{-1}\right)$ data of C VI, for which the actual errors were reported in the original paper. The solid lines are the model values from the calculations with the G16 (black), MCLZ (red), and RCMD (blue) methods. The abbreviations are explained in the text.
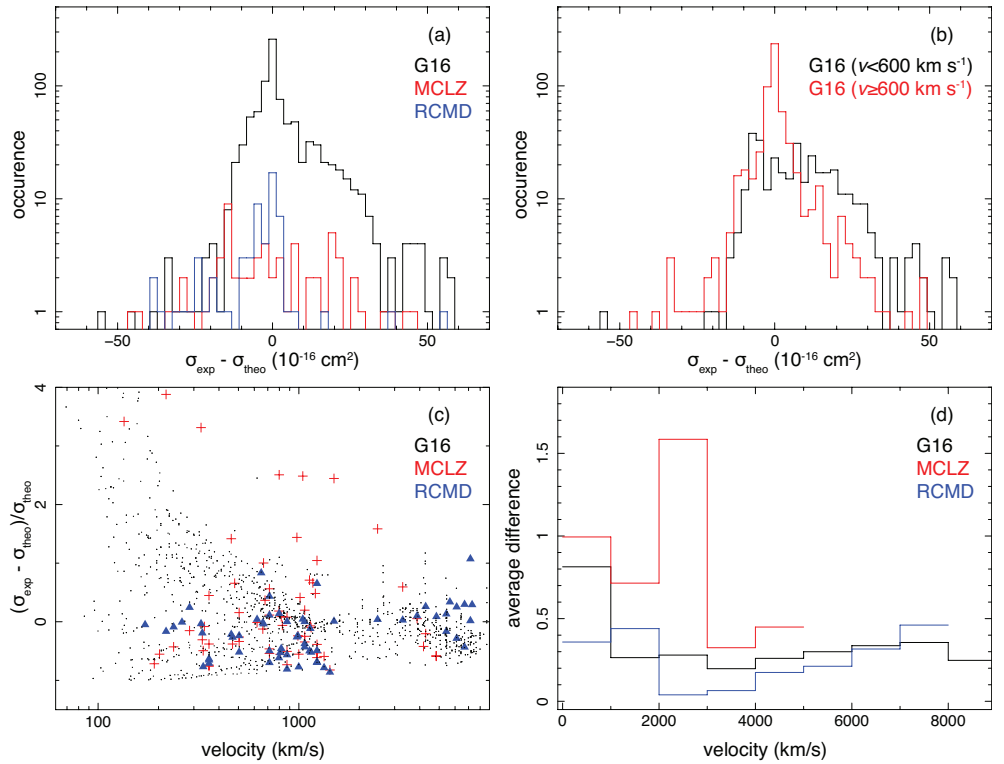

Figure 2. Distributions of the absolute (upper) and relative (lower) deviations of the theoretical cross sections from the experimental results obtained with the measurements summarized in Table 1. (a) Diagrams of the absolute errors for the G16 (black), MCLZ (red), and RCMD (blue) theories. (b) Diagrams of the absolute errors for G16 for low-collision velocities (black) and high velocities (red). (c) The relative deviations for the G16 (black points), MCLZ (red crosses), and RCMD (blue triangles) calculations. (d) The average deviations in absolute values for the three methods in each velocity interval. 
Table 1. Experimental cross section data.

\begin{tabular}{|c|c|c|c|}
\hline Reference & Type $^{a}$ & Ion & Theory Data \\
\hline Shah et al. [44] & total & $\mathrm{Li}^{\mathrm{q}+}(\mathrm{q}=1-3)$ & G16 \\
\hline Seim et al. [45] & total & $\mathrm{Li}^{\mathrm{q}+}(\mathrm{q}=2-3), \mathrm{N}^{\mathrm{q}+}(\mathrm{q}=2-5), \mathrm{Ne}^{\mathrm{q}+}(\mathrm{q}=3-5)$ & G16 \\
\hline Goffe et al. [40] & total & $\mathrm{B}^{\mathrm{q}+}(\mathrm{q}=1-5), \mathrm{C}^{\mathrm{q}+}(\mathrm{q}=1-4)$ & G16 \\
\hline Goffe et al. [40] & total & $\mathrm{C}^{\mathrm{q}+}(\mathrm{q}=5,6), \mathrm{N}^{7+}$ & G16, MCLZ, RCMD \\
\hline McCullough et al. [46] & total & $\mathrm{B}^{2+}, \mathrm{C}^{+}, \mathrm{N}^{+}, \mathrm{Mg}^{2+}$ & G16 \\
\hline Crandall et al. [47] & total & $\mathrm{B}^{\mathrm{q}+}(\mathrm{q}=2-5), \mathrm{C}^{\mathrm{q}+}(\mathrm{q}=3,4), \mathrm{N}^{\mathrm{q}+}(\mathrm{q}=3,4), \mathrm{O}^{\mathrm{q}+}(\mathrm{q}=5,6)$ & G16 \\
\hline Gardner et al. [48] & total & $\mathrm{Bq}^{\mathrm{q}}(\mathrm{q}=2-4), \mathrm{C}^{\mathrm{q}}+(\mathrm{q}=2-4), \mathrm{N}^{\mathrm{q}}+(\mathrm{q}=2-5), \mathrm{O}^{+}(\mathrm{q}=2-5)$ & G16 \\
\hline Phaneuf et al. [49] & total & $\mathrm{C}^{\mathrm{q}+}(\mathrm{q}=1-4), \mathrm{N}^{\mathrm{q}+}(\mathrm{q}=1-5), \mathrm{O}^{\mathrm{q}}+(\mathrm{q}=1-5), \mathrm{Si}^{\mathrm{q}}(\mathrm{q}=2-7)$ & G16 \\
\hline Nutt et al. [50] & total & 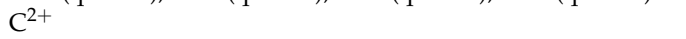 & G16 \\
\hline Phaneuf et al. [41] & total & $\mathrm{C}^{\mathrm{q}+}(\mathrm{q}=3,4), \mathrm{O}^{\mathrm{q}+}(\mathrm{q}=2-6)$ & G16 \\
\hline Phaneuf et al. [41] & total & $\mathrm{C}^{\mathrm{q}+}(\mathrm{q}=5,6)$ & G16, MCLZ, RCMD \\
\hline Sant'Anna et al. [51] & total & $\mathrm{C}^{3+}+1+2-1$ & G16 \\
\hline Ciric et al. [52] & total,nl & $\mathrm{C}^{\mathrm{q}+}(\mathrm{q}=3,4), \mathrm{N}^{5+}, \mathrm{O}^{6+}$ & G16 \\
\hline McCullough et al. [53] & total,nl & 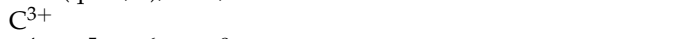 & G16 \\
\hline Panov et al. [42] & total & $\mathrm{C}^{4+}, \mathrm{N}^{5+}, \mathrm{O}^{6+}, \mathrm{Ne}^{8+}$ & G16 \\
\hline Panov et al. [42] & total & $\mathrm{C}^{++}(\mathrm{q}=5,6), \mathrm{N}^{\mathrm{q}+}(\mathrm{q}=6,7), \mathrm{O}^{\mathrm{q}}+(\mathrm{q}=7,8), \mathrm{Ne}^{\mathrm{q}+}(\mathrm{q}=9,10)$ & G16, MCLZ, RCMD \\
\hline Dijkkamp et al. [54] & total,nl & $\mathrm{C}^{\mathrm{q}+}(\mathrm{q}=3,4), \mathrm{N}^{5+}, \mathrm{O}^{6+}$ & G16 \\
\hline Fritsch \& Lin [55] & total,nl & 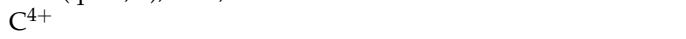 & G16 \\
\hline Hoekstra et al. [56] & total,nl & $\mathrm{C}^{4+}$ & G16 \\
\hline Stebbings et al. [57] & total & $\mathrm{N}^{+}, \mathrm{O}^{+}$ & G16 \\
\hline Fite et al. [58] & total & $\mathrm{O}^{+}$ & G16 \\
\hline Meyer et al. [43] & total & $\mathrm{B}^{\mathrm{q}+}(\mathrm{q}=2-5), \mathrm{C}^{\mathrm{q}+}(\mathrm{q}=3,4), \mathrm{N}^{\mathrm{q}+}(\mathrm{q}=3,4)$ & G16 \\
\hline Meyer et al. [43] & total & $\mathrm{O}^{\mathrm{q}+}(\mathrm{q}=3-6), \mathrm{Si}^{\mathrm{q}+}(\mathrm{q}=4-9), \mathrm{Fe}^{\mathrm{q}+}(\mathrm{q}=4-15)$ & G16 \\
\hline Meyer et al. [43] & total & $\mathrm{O}^{\mathrm{q}}+(\mathrm{q}=7,8)$ & G16, MCLZ, RCMD \\
\hline Havener et al. [59] & total & $\mathrm{O}^{5+}$ & G16 \\
\hline Huber [60] & total & $\mathrm{Ne}^{\mathrm{q}+}(\mathrm{q}=2-4), \mathrm{Ar}^{\mathrm{q}+}(\mathrm{q}=2-4,6)$ & G16 \\
\hline Kim et al. [61] & total & $\mathrm{Si}^{\mathrm{q}}+(\mathrm{q}=2-7)$ & G16 \\
\hline Beijers et al. [62] & $\mathrm{nl}$ & $\mathrm{O}^{3+}$ & G16 \\
\hline Rejoub et al. [63] & total & $\mathrm{Ne}^{3+}$ & G16 \\
\hline Havener et al. [64] & total & $\mathrm{Ne}^{4+}$ & G16 \\
\hline Bruhns et al. [65] & total & $\mathrm{Si}^{3+}$ & G16 \\
\hline Havener et al. [66] & total & $C^{3+}$ & G16 \\
\hline Mroczkowski et al. [67] & total & $\mathrm{Ne}^{2+}$ & G16 \\
\hline Pieksma \& Havener [68] & total & $\mathrm{B}^{4+}$ & G16 \\
\hline Folkerts et al. [69] & total & $\mathrm{N}^{4+}$ & G16 \\
\hline
\end{tabular}

$\bar{a}:$ total $=$ total cross section, $\mathrm{nl}=n l$-resolved cross section.

The laboratory results should have their own uncertainties; however, these values are available for only a part of the measurements. Here, we provide a rough estimate of the combined measurement uncertainty. The mean systematic uncertainties on the cross sections measured in, e.g., Meyer et al. [43], Draganić et al. [70], Cabrera-Trujillo et al. [71], are approximately $15 \%$ for the energy range considered. Assuming that this value can be applied to the other laboratory results, the measurement uncertainties are about $1 \%$ for the sample used in testing the G16 calculation, and $\sim 4 \%$ for the MCLZ and RCMD results. These relatively minor uncertainties can be accepted as the errors of the theoretical deviations obtained above (e.g., 55\%, 88\%, and 35\% for the G16, MCLZ, and RCMD approaches).

The total charge exchange cross section is needed not only for calculating the charge exchange emission, but also to derive the ionization concentration for general cosmic plasmas in collisional ionization or photoionization equilibrium. The uncertainties in the theoretical calculation would introduce systematic uncertainties to the charge state distribution for the low-temperature plasmas where ions and neutral atoms coexist. As shown in Figure 3, we present two test cases on the concentration calculations of $\mathrm{N}$ and $\mathrm{O}$ ions in collisional ionization equilibrium (CIE). Here, we assume uncertainties of $50 \%$ on the charge exchange recombination rates. The induced errors on the charge distributions of $\mathrm{N}$ I and O I would become $10 \%$ and $60 \%$ at an equilibrium temperature of $1.2 \mathrm{eV}$. The difference between $\mathrm{N}$ I and $\mathrm{O}$ I errors reflects the different relative contribution of charge exchange to the total recombination in the concentration calculation. This result suggests that the charge exchange atomic data are vital to the modeling accuracy of lowly ionized species for collisional plasmas. It is expected that similar uncertainties would also apply to photoionization modeling, which includes the charge exchange component in the same way. 

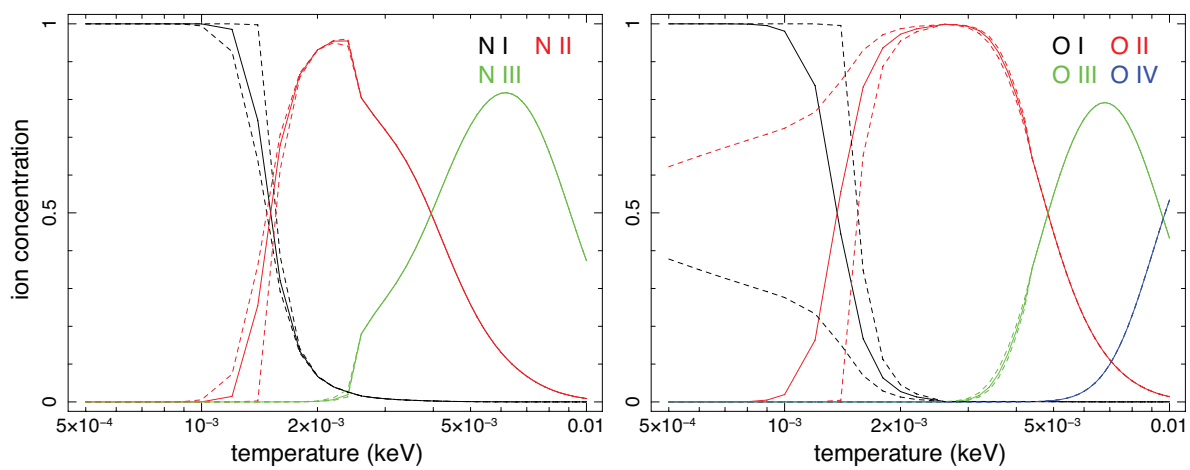

Figure 3. Charge state distributions of $\mathrm{N}$ (left) and $\mathrm{O}$ (right) as a function of equilibrium temperature for the CIE plasma, calculated with SPEX version 3.06.01. The dashed lines show the calculations when the charge exchange recombination rates are changed by $50 \%$, while the other ionization and recombination data are kept intact.

\subsection{Cross Sections for the Peak nl Shells}

Next, we examine the state-resolved cross sections. The selective population of high$n$ levels of the recombining ions is known to be a characteristic property of the charge exchange reaction. The distribution functions on the quantum numbers $n$ and $l$ are key to the calculation of the spectrum, though the present theory still cannot fully reproduce the $n l$ distributions measured in the laboratory $[27,33,72]$.

As shown in Figure 4, we compare the laboratory measurements of four reactions with theoretical calculations, using the G16 method. G16 is the only calculation available in SPEX for the ions tested. It defines empirically $n$ of the most populated levels as functions of the collision velocity, charge, and ionization potential. For the four test cases, G16 successfully predicts the peak $n: n=3$ for C IV and O III, $n=4$ for N V and O VI. The cross sections of the peak $n$ levels, however, show deviations from the G16 values at the low energies. For $C$ IV and O III, the measured values for $v=100 \mathrm{~km} \mathrm{~s}^{-1}$ are higher by a factor of $\sim 2.5$ than the theoretical ones. This is probably because the G16 method underestimates the total cross sections at low energies, as already shown in Figure 2. For $v>500 \mathrm{~km} \mathrm{~s}^{-1}$, the G16 calculations become consistent, with the measurements within $40 \%$ for the peak $n$.

To assess the $l$-distribution function, in Figure 4, we also compare the cross sections of the $n p$ subshells. The $l$-distribution defined in G16 is a smooth function that switches as a function of velocity between the different empirical $l$ distributions introduced in Janev \& Winter [73] (see also Equations (4)-(8) and Appendix B in [13]). The G16 cross sections on the $n p$ shells are lower, by a factor of 2-5, than the experimental values for $v<500 \mathrm{~km} \mathrm{~s}^{-1}$. The deviations again become much smaller at higher velocities. To summarize above, the G16 method could reproduce the $n l$-resolved cross sections for the test cases with an accuracy of $\sim 40 \%$ for $v>500 \mathrm{~km} \mathrm{~s}^{-1}$, while for the low-velocity collision, the G16 cross sections, as well as the line intensities calculated based on the atomic data, are much less reliable. 

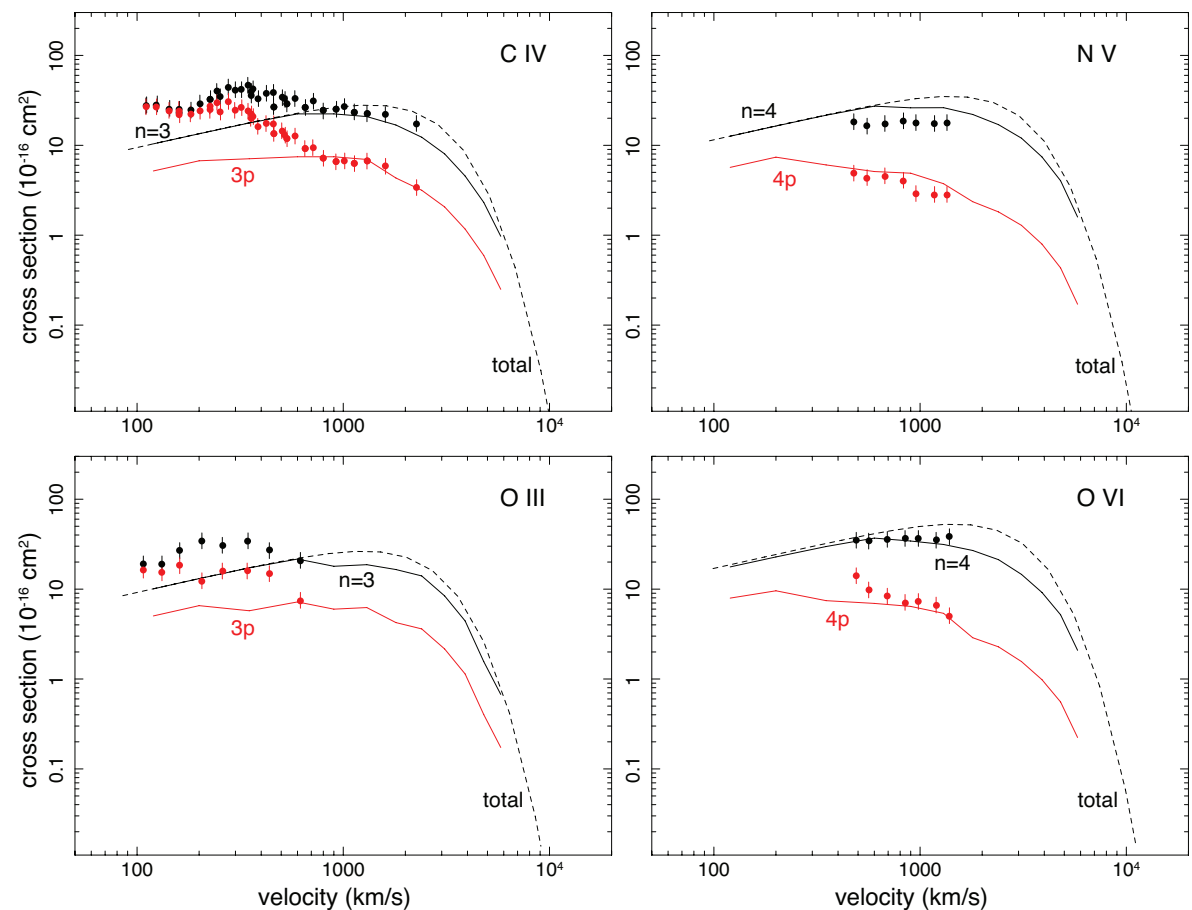

Figure 4. State-selective cross sections as a function of collision velocity for C IV, N V, O III, and O VI. The data points are taken from merged-beam experiments (see Table 1 for detail), for the peak $n$ shells (black) and the $n p$ subshells (red). The approximate errors of $15 \%$ [43] are shown. The black solid lines are the G16 calculations of the peak $n$ shells, and the red lines are the G16 data for the $n p$ subshells. The dash lines are the G16 calculations of the total cross sections.

\subsection{Line Ratios}

The large ratios between $1 s-n p(n>2)$ and $1 s-2 p$ lines are often used as characteristic diagnostics of the highly charged charge exchange plasma [10,11]. It is known that the line ratios would decrease with increasing collision velocity, because a high-speed collision might yield captures on high angular momentum states, producing more $1 s-2 p$ transitions through cascade. So, the line ratios can often be utilized as a probe of collision velocity $[27,74]$. The accuracy of the velocity measurement is therefore determined by the quality of the atomic data.

In Figure 5, we plot the comparison of the line ratio calculations and experiments for $\mathrm{C}$ VI and O VIII. The experimental data are taken from the beam-gas measurements by Andrianarijaona et al. [75] for C VI and Seely et al. [76] for O VIII. A caveat of the comparison is that these experiments used the $\mathrm{Kr}$ atom as a target, while the original theoretical calculations are based on capture from $\mathrm{H}$ atom. As reported in Leung \& Kirchner [77], the line ratios from $\mathrm{Kr}$ and $\mathrm{H}$ collisions are somewhat different, in particular for the lowenergy regime, even though the ionization potentials of $\mathrm{Kr}$ and $\mathrm{H}$ atoms are nearly the same. To compensate this discrepancy, we calculate the $\mathrm{H}$-to-Kr scalings as a function of velocities on both C VI and O VIII line ratios, using the theoretical results reported in Leung \& Kirchner [77] (in their Figures 3 and 6), and apply the scalings to the G16, MCLZ, and RCMD line ratios. The scaled line ratios should represent a better approximation to the collisions with the $\mathrm{Kr}$ target. 

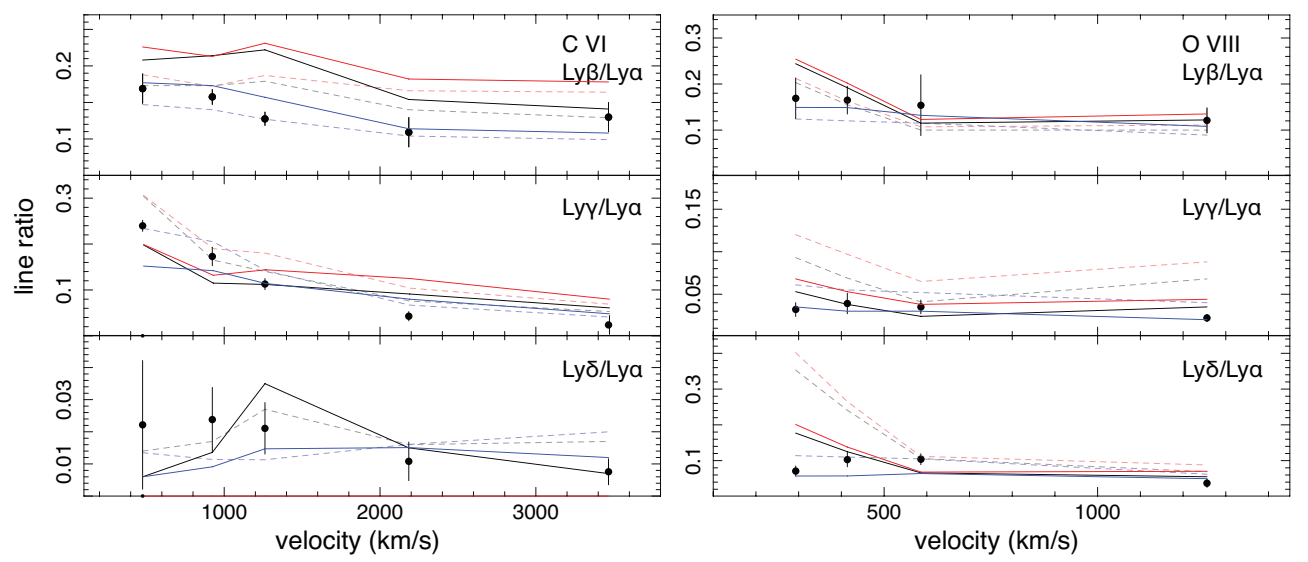

Figure 5. Comparison of experimental and theoretical line ratios for the $\mathrm{C}^{6+}$ (left) and $\mathrm{O}^{8+}$ (right) reactions. The experimental data from Andrianarijaona et al. [75] and Seely et al. [76] are plotted as data points, and the predictions from G16, MCLZ, and RCMD are shown in black, red, and blue curves. The dashed curves show the calculations of $\mathrm{C}^{6+}$ and $\mathrm{O}^{8+}$ collisions with $\mathrm{H}$ atoms, and the solid lines show the collisions with $\mathrm{Kr}$ atoms obtained using the scaling of Leung \& Kirchner [77].

As shown in Figure 5, the experiments and calculations yield the same peak $n, n=4$ for C VI and $n=5$ for O VIII, though the line ratios still differ at several velocities. One of the main discrepancies occurs between the scaled G16/MCLZ and the lab data for the $\mathrm{C}$ VI $\operatorname{Ly} \beta / \operatorname{Ly} \alpha$ line ratio, where the two theoretical values exceed the measured one by about $70 \%$ at $v=1000 \mathrm{~km} \mathrm{~s}^{-1}$. The RCMD calculation shows better agreement with the lab values on this line ratio.

A more extensive comparison can be seen in Table 2. It is a compilation of several laboratory efforts, including the recent electron beam ion trap devices with X-ray spectral analysis carried out at both low and high resolutions. The EBIT devices simulate charge exchange reactions only at low collision energies. The average relative discrepancies (experiment-theory/theory) of the line ratios are $0.63,0.77$, and 0.54 for the G16, MCLZ, and RCMD calculations, respectively. For the peak $n$ shell, the average discrepancies are $0.61,0.81$, and 0.56 for the three models. These differences are significantly larger than those on the modeling of collisional ionization equilibrium plasmas $(\sim 10-40 \%,[14,78,79])$, suggesting that the state-of-the-art charge exchange spectral models, even with dedicated theoretical calculations, are still less reliable than those for the CIE plasma.

Table 2. Experimental and theoretical Line ratios.

\begin{tabular}{|c|c|c|c|c|c|c|c|}
\hline Ion & $v\left(\mathrm{~km} \mathrm{~s}^{-1}\right)$ & Ratio & Experiment & G16 & MCLZ & RCMD & Reference $^{a}$ \\
\hline \multirow[t]{2}{*}{ N VII } & 794 & $\operatorname{Ly} \beta / \operatorname{Ly} \alpha$ & 0.76 & 0.12 & 0.13 & 0.10 & 1 \\
\hline & & $(\operatorname{Ly} \gamma+\operatorname{Ly} \delta) / \operatorname{Ly} \alpha$ & 0.62 & 0.18 & 0.20 & 0.29 & \\
\hline \multirow[t]{2}{*}{ O VII } & 724 & $\operatorname{Ly} \beta / \operatorname{Ly} \alpha$ & 0.19 & 0.07 & 0.09 & 0.07 & \\
\hline & & $(\operatorname{Ly} \gamma+\operatorname{Ly} \delta) / \operatorname{Ly} \alpha$ & 0.24 & 0.11 & 0.47 & 0.07 & \\
\hline \multirow[t]{2}{*}{ O VIII } & 774 & $\operatorname{Ly} \beta / \operatorname{Ly} \alpha$ & 0.13 & 0.11 & 0.10 & 0.11 & \\
\hline & & $(\operatorname{Ly} \gamma+\operatorname{Ly} \delta) / \operatorname{Ly} \alpha$ & 0.17 & 0.15 & 0.18 & 0.14 & \\
\hline \multirow[t]{2}{*}{ Ne IX } & 743 & $\operatorname{Ly} \beta / \operatorname{Ly} \alpha$ & 0.04 & 0.04 & 0.12 & - & \\
\hline & & $(\operatorname{Ly} \gamma+\operatorname{Ly} \delta) / \operatorname{Ly} \alpha$ & 0.05 & 0.05 & 0.18 & - & \\
\hline \multirow[t]{2}{*}{$\mathrm{Ne} X$} & 783 & $\operatorname{Ly} \beta / \operatorname{Ly} \alpha$ & 0.12 & 0.08 & 0.08 & 0.08 & \\
\hline & & $(\operatorname{Ly} \gamma+\operatorname{Ly} \delta) / \operatorname{Ly} \alpha$ & 0.11 & 0.06 & 0.08 & 0.04 & \\
\hline \multirow[t]{4}{*}{ O VIII } & 293 & $\operatorname{Ly} \beta / \operatorname{Ly} \alpha$ & $0.169 \pm 0.044$ & $0.244^{b}$ & 0.254 & 0.149 & 2 \\
\hline & & $\operatorname{Ly} \gamma / \operatorname{Ly} \alpha$ & $0.032 \pm 0.008$ & 0.053 & 0.068 & 0.035 & \\
\hline & & $\operatorname{Ly} \delta / \operatorname{Ly} \alpha$ & $0.071 \pm 0.014$ & 0.177 & 0.201 & 0.057 & \\
\hline & & $\operatorname{Ly} \epsilon / \operatorname{Ly} \alpha$ & $0.0065 \pm 0.003$ & 0.054 & 0.0061 & 0.027 & \\
\hline \multirow[t]{4}{*}{ O VIII } & 414 & $\operatorname{Ly} \beta / \operatorname{Ly} \alpha$ & $0.165 \pm 0.030$ & 0.192 & 0.202 & 0.149 & \\
\hline & & $\operatorname{Ly} \gamma / \operatorname{Ly} \alpha$ & $0.039 \pm 0.012$ & 0.038 & 0.053 & 0.030 & \\
\hline & & $\operatorname{Ly} \delta / \operatorname{Ly} \alpha$ & $0.103 \pm 0.02$ & 0.125 & 0.138 & 0.057 & \\
\hline & & $\operatorname{Ly} \epsilon / \operatorname{Ly} \alpha$ & $0.005 \pm 0.0076$ & 0.031 & 0.0024 & 0.019 & \\
\hline \multirow[t]{4}{*}{ O VIII } & 586 & $\operatorname{Ly} \beta / \operatorname{Ly} \alpha$ & $0.154 \pm 0.006$ & 0.115 & 0.123 & 0.132 & \\
\hline & & $\operatorname{Ly} \gamma / \operatorname{Ly} \alpha$ & $0.035 \pm 0.008$ & 0.024 & 0.038 & 0.030 & \\
\hline & & $\operatorname{Ly} \delta / \operatorname{Ly} \alpha$ & $0.104 \pm 0.015$ & 0.066 & 0.068 & 0.064 & \\
\hline & & $\operatorname{Ly} \epsilon / \operatorname{Ly} \alpha$ & $0.0048 \pm 0.0061$ & 0.015 & 0.00086 & 0.014 & \\
\hline
\end{tabular}


Table 2. Cont.

\begin{tabular}{|c|c|c|c|c|c|c|c|}
\hline Ion & $v\left(\mathrm{~km} \mathrm{~s}^{-1}\right)$ & Ratio & Experiment & G16 & MCLZ & RCMD & Reference ${ }^{a}$ \\
\hline \multirow[t]{4}{*}{ O VIII } & 1256 & $\operatorname{Ly} \beta / \operatorname{Ly} \alpha$ & $0.121 \pm 0.027$ & 0.122 & 0.135 & 0.108 & \\
\hline & & $\operatorname{Ly} \gamma / \operatorname{Ly} \alpha$ & $0.022 \pm 0.004$ & 0.035 & 0.044 & 0.020 & \\
\hline & & $\operatorname{Ly} \delta / \operatorname{Ly} \alpha$ & $0.037 \pm 0.011$ & 0.055 & 0.071 & 0.050 & \\
\hline & & $\mathrm{Ly} \epsilon / \operatorname{Ly} \alpha$ & $0.0048 \pm 0.0028$ & 0.023 & 0.00045 & 0.0090 & \\
\hline \multirow[t]{3}{*}{ C VI } & 477 & $\operatorname{Ly} \beta / \operatorname{Ly} \alpha$ & $0.169 \pm 0.023$ & $0.208^{b}$ & 0.226 & 0.177 & 3 \\
\hline & & $\operatorname{Ly} \gamma / \operatorname{Ly} \alpha$ & $0.240 \pm 0.012$ & 0.198 & 0.199 & 0.152 & \\
\hline & & $\operatorname{Ly} \delta / \operatorname{Ly} \alpha$ & $0.022 \pm 0.020$ & 0.0062 & $\begin{array}{c}2.8 \\
\times 10^{-6}\end{array}$ & 0.0061 & \\
\hline \multirow[t]{3}{*}{ C VI } & 924 & $\operatorname{Ly} \beta / \operatorname{Ly} \alpha$ & $0.157 \pm 0.012$ & 0.214 & 0.213 & 0.173 & \\
\hline & & $\operatorname{Ly} \gamma / \operatorname{Ly} \alpha$ & $0.173 \pm 0.023$ & 0.115 & 0.132 & 0.142 & \\
\hline & & $\operatorname{Ly} \delta / \operatorname{Ly} \alpha$ & $0.024 \pm 0.009$ & 0.014 & $\begin{array}{l}2.7 \\
\times 10^{-6}\end{array}$ & 0.0091 & \\
\hline \multirow[t]{3}{*}{ C VI } & 1262 & $\operatorname{Ly} \beta / \operatorname{Ly} \alpha$ & $0.128 \pm 0.009$ & 0.222 & $\hat{0.231}$ & 0.157 & \\
\hline & & $\operatorname{Ly} \gamma / \operatorname{Ly} \alpha$ & $0.113 \pm 0.012$ & 0.112 & 0.144 & 0.114 & \\
\hline & & $\operatorname{Ly} \delta / \operatorname{Ly} \alpha$ & $0.021 \pm 0.008$ & 0.035 & $\begin{array}{c}2.2 \\
\times 10^{-6}\end{array}$ & 0.015 & \\
\hline \multirow[t]{3}{*}{ C VI } & 2185 & $\operatorname{Ly} \beta / \operatorname{Ly} \alpha$ & $0.109 \pm 0.019$ & 0.154 & 0.182 & 0.114 & \\
\hline & & $\operatorname{Ly} \gamma / \operatorname{Ly} \alpha$ & $0.043 \pm 0.011$ & 0.091 & 0.125 & 0.080 & \\
\hline & & $\operatorname{Ly} \delta / \operatorname{Ly} \alpha$ & $0.011 \pm 0.006$ & 0.015 & $\begin{array}{l}6.7 \\
\times 10^{-7}\end{array}$ & 0.015 & \\
\hline \multirow[t]{3}{*}{ C VI } & 3466 & $\operatorname{Ly} \beta / \operatorname{Ly} \alpha$ & $0.130 \pm 0.021$ & 0.141 & 0.178 & 0.108 & \\
\hline & & $\operatorname{Ly} \gamma / \operatorname{Ly} \alpha$ & $0.024 \pm 0.018$ & 0.061 & 0.080 & 0.048 & \\
\hline & & $\operatorname{Ly} \delta / \operatorname{Ly} \alpha$ & $0.0076 \pm 0.004$ & 0.007 & $\begin{array}{l}5.0 \\
\times 10^{-7}\end{array}$ & 0.012 & \\
\hline O VII & low & $\mathrm{He}_{\text {high }} / \mathrm{He} \alpha$ & 0.167 & 0.168 & 0.152 & 0.058 & 4 \\
\hline Ne IX & low & $\mathrm{He}_{\text {high }} / \mathrm{He} \alpha$ & 0.162 & 0.161 & 0.133 & - & \\
\hline $\begin{array}{c}\mathrm{Ar} \\
\text { XVII }\end{array}$ & low & $\mathrm{He}_{\text {high }} / \mathrm{He} \alpha$ & 0.191 & 0.133 & - & - & \\
\hline$\underset{\text { XXV }}{\mathrm{Fe}}$ & low & $\mathrm{He}_{\text {high }} / \mathrm{He} \alpha$ & 0.267 & 0.156 & 0.079 & - & \\
\hline O VIII & low & $\operatorname{Ly}_{\text {high }} /$ Ly $\alpha$ & 1.006 & 0.786 & 0.887 & 0.366 & \\
\hline $\mathrm{NeX}$ & low & $\mathrm{Ly}_{\text {high }} / \mathrm{Ly} \alpha$ & 1.207 & 0.690 & 0.865 & 0.210 & \\
\hline $\mathrm{Mg}$ XII & low & $\operatorname{Ly} \beta / \operatorname{Ly} \alpha$ & $0.227 \pm 0.040$ & 0.179 & 0.205 & - & 5 \\
\hline Mg XII & low & $\operatorname{Ly} \gamma / \operatorname{Ly} \alpha$ & $0.133 \pm 0.022$ & 0.070 & 0.083 & - & \\
\hline Mg XII & low & $\operatorname{Ly} \delta / \operatorname{Ly} \alpha$ & $0.044 \pm 0.015$ & 0.038 & 0.046 & - & \\
\hline Mg XII & low & $\operatorname{Ly} \epsilon / \operatorname{Ly} \alpha$ & $0.095 \pm 0.015$ & 0.028 & 0.030 & - & \\
\hline Mg XII & low & $\operatorname{Ly} \zeta / \operatorname{Ly} \alpha$ & $0.030 \pm 0.018$ & 0.221 & 0.120 & - & \\
\hline Mg XII & low & $\operatorname{Ly} \eta / \operatorname{Ly} \alpha$ & $0.080 \pm 0.014$ & 0.091 & 0.287 & - & \\
\hline SXVI & low & $\operatorname{Ly} \beta / \operatorname{Ly} \alpha$ & $0.203 \pm 0.070$ & 0.153 & 0.171 & - & 5 \\
\hline SXVI & low & $\operatorname{Ly} \gamma / \operatorname{Ly} \alpha$ & $0.082 \pm 0.016$ & 0.055 & 0.064 & - & \\
\hline S XVI & low & $\operatorname{Ly} \delta / \operatorname{Ly} \alpha$ & $0.053 \pm 0.011$ & 0.028 & 0.033 & - & \\
\hline S XVI & low & $\operatorname{Ly} \epsilon / \operatorname{Ly} \alpha$ & $0.053 \pm 0.008$ & 0.017 & 0.020 & - & \\
\hline S XVI & low & $\operatorname{Ly} \zeta / \operatorname{Ly} \alpha$ & $0.016 \pm 0.005$ & 0.012 & 0.014 & - & \\
\hline SXVI & low & $\mathrm{Ly} \eta / \operatorname{Ly} \alpha$ & $0.029 \pm 0.008$ & 0.024 & 0.014 & - & \\
\hline S XVI & low & $\operatorname{Ly} \theta / \operatorname{Ly} \alpha$ & $0.111 \pm 0.019$ & 0.149 & 0.101 & - & \\
\hline S XVI & low & $\operatorname{Ly} \iota / \operatorname{Ly} \alpha$ & $0.165 \pm 0.024$ & 0.058 & 0.165 & - & \\
\hline
\end{tabular}

$\bar{a}$ : references 1 = Greenwood et al. [72]; 2 = Seely et al. [76]: $3=$ Andrianarijaona et al. [75]; $4=$ Wargelin et al. [80]; 5 = Betancourt-Martinez [81]. ${ }^{b}:$ H-to-Kr scaling has been applied to the theoretical line ratios for O VIII and C VI; see text for details.

\section{Discussion and Ending Remarks}

Based on a large sample of laboratory measurements, we have systematically compared the commonly used charge exchange atomic data to the experimental results. The G16, MCLZ, and RCMD calculations utilized in the SPEX code do not fully reproduce the measurements, with notable, and likely velocity-dependent discrepancies in both total cross sections, state-resolved cross sections, and line ratios in the $\mathrm{X}$-ray spectra. While the ease of the use of the present CX model is beneficial for the X-ray astronomical community, it should be used with caution, in particular for non-charge-exchange experts. The unresolvable disagreements call for advanced theoretical calculations for especially the low collision energy regime, in combination with more laboratory measurements with, in particular, EBIT and COLTRIMS facilities.

The previous EBIT experiments have provided relevant benchmarks to the predicted cross sections for electron capture into specific principal quantum number states $n$. However, a comparison with the angular-momentum $l$-resolved cross sections is challenging, as they depend on the collision energy; and the EBIT measurements are limited to low collision energies $(<10 \mathrm{eV} / \mathrm{u})$ [27]. Besides, the charge exchange process not only produces $X$-ray lines, but also generates lines in the ultraviolet and optical band as the Rydberg levels populated by charge exchange relax through radiative cascades to the ground state of the ion. Thus, the simultaneous measurements of EUV and optical charge exchange cascade 
photons at the EBIT would be of interest, and they could provide additional information on the population of $n l$-states for plasma modeling [29]. Furthermore, possible multi-electron capture contributions from the molecular targets used in the EBIT measurements can also be avoided by using an atomic hydrogen target, where only single-electron capture can occur [82]. Atomic hydrogen is of particular interest as it is also the most abundant neutral element in the universe, and it makes a comparison between laboratory measurements and astrophysical observations more reliable.

Besides EBIT, the COLTRIMS and beam-gas experiments have been providing reliable measurements on velocity-dependent total and state-resolved cross sections. The improvement in the momentum measurement technique allows $n l$ selectivity, and for a few cases, it might even be able to resolve the spin state. The state-of-the-art measurement accuracy is about $11 \%$ for both the total and $n l$-resolved cross sections [83].

A systematic measurement of the cosmic abundant ions with the COLTRIMS facilities, in combination with simultaneous EBIT X-ray spectroscopy, is desirable for the astronomical community. A consistent and continuous effort will be needed to ensure that the charge exchange atomic data will be ready for the high-resolution X-ray spectra taken with nextgeneration missions, XRISM (launch due in 2023, [84]) and Athena (early 2030s, [85]).

Assessing uncertainties carried out by the theoretical atomic data is also vital to the success of the upcoming missions. The atomic physics and plasma code community has already begun this work, with a persistent effort on the evaluation of the errors on electron impact excitation and transition probability data [14,86-90], as well as errors on photon impact data and modeling [91]. One implication from the aforementioned works, including the present work on the charge exchange modeling, is that the classical assumption of constant model uncertainty (e.g., 20\% on line emissivity) is no longer valid, since the uncertainties are proven to vary significantly with the underlying model and its key parameters.

Author Contributions: Conceptualization, L.G., C.S. and R.Z.; Data curation, L.G.; Formal analysis, L.G.; Investigation, L.G.; Methodology, L.G.; Project administration, L.G.; Writing-original draft, L.G., C.S. and R.Z.; Writing-review \& editing, L.G., C.S. and R.Z. All authors have read and agreed to the published version of the manuscript.

Funding: This research was funded by European Union's Horizon 2020 Programme under the AHEAD2020 project grant agreement n. 871158 .

Acknowledgments: SRON is supported financially by NWO, the Netherlands Organization for Scientific Research. C.S. acknowledge support from an appointment to the NASA Postdoctoral Program at the NASA Goddard Space Flight Center, administered by the Universities Space Research Association, under contract with NASA, by the Lawrence Livermore National Laboratory (LLNL) Visiting Scientist and Professional Program Agreement, and by Max-Planck-Gesellschaft (MPG).

Conflicts of Interest: The authors declare no conflict of interest.

\section{References}

1. Lisse, C.M.; Denner, 1.K.; Englhauser, J.; Harden, M.; Marshall, F.E.; Mumma, M.J.; Petre, R.; Pye, J.P.; Ricketts, M.J.; Schmitt, J.; et al. Discovery of X-ray and Extreme Ultraviolet Emission from Comet C/Hyakutake 1996 B2. Science 1996, 274, 205-209. [CrossRef]

2. Cravens, T.E. Comet Hyakutake X-ray source: Charge transfer of solar wind heavy ions. Geophys. Res. Lett. 1997, $24,105-108$. [CrossRef]

3. Bodewits, D.; Christian, D.J.; Torney, M.; Dryer, M.; Lisse, C.M.; Dennerl, K.; Zurbuchen, T.H.; Wolk, S.J.; Tielens, A.G.G.M.; Hoekstra, R. Spectral analysis of the Chandracomet survey. Astron. Astrophys. 2007, 469, 1183-1195. [CrossRef]

4. Branduardi-Raymont, G.; Bhardwaj, A.; Elsner, R.F.; Gladstone, G.R.; Ramsay, G.; Rodriguez, P.; Soria, R.; Waite, J.H., Jr.; Cravens, T.E. A study of Jupiter's aurorae with XMM-Newton. Astron. Astrophys. 2006, 463, 761-774. [CrossRef]

5. Katsuda, S.; Tsunemi, H.; Mori, K.; Uchida, H.; Kosugi, H.; Kimura, M.; Nakajima, H.; Takakura, S.; Petre, R.; Hewitt, J.W.; et al. Possible charge-exchange X-ray emission in the cygnus loop detected withsuzaku. Astrophys. J. 2011, 730, 24. [CrossRef]

6. Cumbee, R.S.; Henley, D.B.; Stancil, P.C.; Shelton, R.L.; Nolte, J.L.; Wu, Y.; Schultz, D.R. Can charge exchange explain anomalous soft X-ray emission in the cygnus loop? Astrophys. J. 2014, 787, L31. [CrossRef] 
7. Liu, J.; Wang, Q.D.; Li, Z.; Peterson, J.R. X-ray spectroscopy of the hot gas in the M31 bulge. Mon. Not. R. Astron. Soc. 2010, 404, 1879. [CrossRef]

8. Zhang, S.; Wang, Q.D.; Ji, L.; Smith, R.K.; Foster, A.R.; Zhou, X. Spectral modeling of the charge-exchange X-ray emission from M82. Astrophys. J. 2014, 794, 61. [CrossRef]

9. Gu, L.; Mao, J.; O’Dea, C.P.; Baum, S.A.; Mehdipour, M.; Kaastra, J.S. Charge exchange in the ultraviolet: Implication for interacting clouds in the core of NGC 1275. Astron. Astrophys. 2017, 601, A45. [CrossRef]

10. Gu, L.; Kaastra, J.; Raassen, A.J.J.; Mullen, P.D.; Cumbee, R.; Lyons, D.; Stancil, P.C. A novel scenario for the possible X-ray line feature at $\sim 3.5 \mathrm{keV}$. Astron. Astrophys. 2015, 584, L11. [CrossRef]

11. Gu, L.; Mao, J.; de Plaa, J.; Raassen, A.J.J.; Shah, C.; Kaastra, J. Charge exchange in galaxy clusters. Astron. Astrophys. 2018, 611, A26. [CrossRef]

12. Smith, R.; Foster, A.; Brickhouse, N. Approximating the X-ray spectrum emitted from astrophysical charge exchange. Astron. Nachrichten 2012, 333, 301-304. [CrossRef]

13. Gu, L.; Kaastra, J.; Raassen, A.J.J. Plasma code for astrophysical charge exchange emission at X-ray wavelengths. Astron. Astrophys. 2016, 588, A52. [CrossRef]

14. Akamatsu, H.; Akimoto, F.; Allen, S.W.; Angelini, L.; Audard, M.; Awaki, H.; Axelsson, M.; Bamba, A.; Bautz, M.W.; Blandford, R.; et al. Atomic data and spectral modeling constraints from high-resolution X-ray observations of the Perseus cluster with Hitomi. Publ. Astron. Soc. Jpn. 2018, 70, 12. [CrossRef]

15. Bodewits, D.; Juhász, Z.; Hoekstra, R.; Tielens, A.G.G.M. Catching Some Sun: Probing the Solar Wind with Cometary X-ray and Far-Ultraviolet Emission. Astrophys. J. 2004, 606, L81-L84. [CrossRef]

16. Dijkkamp, D.; Gordeev, Y.S.; Brazuk, A.; Drentje, A.G.; De Heer, F.J. Selective single-electron capture into (n, l) subshells in slow collisions of $\mathrm{C}^{6+}, \mathrm{N}^{6+}, \mathrm{O}^{6+}$ and $\mathrm{Ne}^{6+}$ with $\mathrm{He}, \mathrm{H}_{2}$ and Ar. J. Phys. B At. Mol. Phys. 1985, 18, 737-756. [CrossRef]

17. Trassinelli, M.; Prigent, C.; Lamour, E.; Mezdari, F.; Mérot, J.; Reuschl, R.; Rozet, J.-P.; Steydli, S.; Vernhet, D. Investigation of slow collisions for (quasi) symmetric heavy systems: What can be extracted from high resolution X-ray spectra. J. Phys. B At. Mol. Opt. Phys. 2012, 45, 085202. [CrossRef]

18. Beiersdorfer, P. Highly charged ions in magnetic fusion plasmas: Research opportunities and diagnostic necessities. J. Phys. B At. Mol. Opt. Phys. 2015, 48, 144017. [CrossRef]

19. Lepson, J.K.; Beiersdorfer, P.; Bitter, M.; Roquemore, A.L.; Hill, K.; Kaita, R. Charge exchange produced emission of carbon in the extreme ultraviolet spectral region. J. Phys. Conf. Ser. 2015, 583, 012012. [CrossRef]

20. Rosmej, F.B.; Lisitsa, V.S.; Schott, R.; Dalimier, E.; Riley, D.; Delserieys, A.; Renner, O.; Krousky, E. Charge-exchange-driven X-ray emission from highly ionized plasma jets. EPL Europhys. Lett. 2006, 76, 815-821. [CrossRef]

21. Ali, R.; Beiersdorfer, P.; Harris, C.L.; Neill, P.A. Charge-exchange X-ray spectra: Evidence for significant contributions from radiative decays of doubly excited states. Phys. Rev. A 2016, 93, 012711. [CrossRef]

22. Ali, R.; Neill, P.A.; Beiersdorfer, P.; Harris, C.L.; Raković, M.J.; Wang, J.G.; Schultz, D.R.; Stancil, P.C. On the Significance of the Contribution of Multiple-Electron Capture Processes to Cometary X-ray Emission. Astrophys. J. 2005, 629, L125-L128. [CrossRef]

23. Ali, R.; Neill, P.A.; Beiersdorfer, P.; Harris, C.L.; Schultz, D.R.; Stancil, P.C. Critical test of simulations of charge-exchange-induced X-ray emission in the solar system. Astrophys. J. 2010, 716, L95-L98. [CrossRef]

24. Fischer, D.; Feuerstein, B.; Dubois, R.D.; Moshammer, R.; López-Urrutia, J.C.; Draganic, I.; Lörch, H.; Perumal, A.N.; Ullrich, J. State-resolved measurements of single-electron capture in slow $\mathrm{Ne}^{7+}$-and $\mathrm{Ne}^{8+}$-helium collisions. J. Phys. B At. Mol. Opt. Phys. 2002, 35, 1369. [CrossRef]

25. Xue, Y.; Ginzel, R.; Krauß, A.; Bernitt, S.; Schöffler, M.; Kühnel, K.U.; López-Urrutia, J.R.C.; Moshammer, R.; Cai, X.; Ullrich, J.; et al. Kinematically complete study of electron transfer and rearrangement processes in slow Ar16+-Ne collisions. Phys. Rev. A 2014, 90, 052720. [CrossRef]

26. Allen, F.I.; Biedermann, C.; Radtke, R.; Fussmann, G.; Fritzsche, S. Energy dependence of angular momentum capture states in charge exchange collisions between slow highly charged argon ions and argon neutrals. Phys. Rev. A 2008, 78, 032705. [CrossRef]

27. Beiersdorfer, P.; Olson, R.E.; Brown, G.V.; Chen, H.; Harris, C.L.; Neill, P.A.; Schweikhard, L.; Utter, S.B.; Widmann, K. X-ray Emission Following Low-Energy Charge Exchange Collisions of Highly Charged Ions. Phys. Rev. Lett. 2000, 85, 5090-5093. [CrossRef]

28. Betancourt-Martinez, G.L.; Beiersdorfer, P.; Brown, G.; Kelley, R.L.; Kilbourne, C.A.; Koutroumpa, D.; Leutenegger, M.; Porter, F. Observation of highly disparate K-shell X-ray spectra produced by charge exchange with bare mid-Zions. Phys. Rev. A 2014, 90, 052723. [CrossRef]

29. Dobrodey, S. The Faculty of Physics and Astronomy. Ph.D. Thesis, Heidelberg University, Heidelberg, Germany, 2019.

30. Leutenegger, M.A.; Beiersdorfer, P.; Brown, G.; Kelley, R.L.; Kilbourne, C.A.; Porter, F.S. Measurement of Anomalously Strong Emission from the 1s-9p Transition in the Spectrum of H-Like Phosphorus Following Charge Exchange with Molecular Hydrogen. Phys. Rev. Lett. 2010, 105, 063201. [CrossRef] [PubMed]

31. Shah, C.; Dobrodey, S.; Bernitt, S.; Steinbrügge, R.; López-Urrutia, J.R.C.; Gu, L.; Kaastra, J. Laboratory measurements compellingly support a charge-exchange mechanism for the "dark matter" 3.5 kev X-ray line. Astrophys. J. 2016, 833, 52. [CrossRef]

32. Wargelin, B.J.; Beiersdorfer, P.; Neill, P.A.; Olson, R.E.; Scofield, J.H. Charge-Exchange Spectra of Hydrogenic and He-like Iron. Astrophys. J. 2005, 634, 687-697. [CrossRef] 
33. Betancourt-Martinez, G.L.; Beiersdorfer, P.; Brown, G.V.; Cumbee, R.S.; Hell, N.; Kelley, R.L.; Kilbourne, C.A.; Leutenegger, M.A.; Lockard, T.E.; Porter, F.S. High-resolution Charge Exchange Spectra with L-shell Nickel Show Striking Differences from Models. Astrophys. J. Lett. 2018, 868, L17. [CrossRef]

34. Xu, J.W.; Xu, C.X.; Zhang, R.T.; Zhu, X.L.; Feng, W.T.; Gu, L.; Liang, G.Y.; Guo, D.L.; Gao, Y.; Zhao, D.M.; et al. Measurement of n-resolved State-selective Charge Exchange in $\mathrm{Ne}(8,9)+$ Collision with He and H2. Astrophys. J. Suppl. Ser. 2021, $253,13$. [CrossRef]

35. Kaastra, J.S.; Mewe, R.; Nieuwenhuijzen, H. SPEX: a new code for spectral analysis of X \& UV spectra. In UV and X-ray Spectroscopy of Astrophysical and Laboratory Plasmas; University of California: Berkeley, CA, USA, 1996; pp. 411-414.

36. Mullen, P.D.; Cumbee, R.S.; Lyons, D.; Stancil, P.C. Charge exchange-induced X-ray emission of fe xxv and fe xxvi via a streamlined model. Astrophys. J. Suppl. Ser. 2016, 224, 31. [CrossRef]

37. Wu, Y.; Stancil, P.C.; Schultz, D.R.; Hui, Y.; Liebermann, H.P.; Buenker, R.J. Theoretical investigation of total and state-dependent charge exchange in O6+ collisions with atomic hydrogen. J. Phys. B At. Mol. Opt. Phys. 2012, 45, 235201. [CrossRef]

38. Wu, Y.; Stancil, P.C.; Liebermann, H.P.; Funke, P.; Rai, S.N.; Buenker, R.J.; Schultz, D.R.; Hui, Y.; Draganic, I.N.; Havener, C.C. Theoretical investigation of charge transfer between N6+ and atomic hydrogen. Phys. Rev. A 2011, 84, 022711. [CrossRef]

39. Nolte, J.L.; Stancil, P.C.; Liebermann, H.P.; Buenker, R.J.; Hui, Y.; Schultz, D.R. Final-state-resolved charge exchange in C5+ collisions with H. J. Phys. B At. Mol. Opt. Phys. 2012, 45, 245202. [CrossRef]

40. Goffe, T.V.; Shah, M.B.; Gilbody, H.B. One-electron capture and loss by fast multiply charged boron and carbon ions in $\mathrm{H}_{\text {and }} \mathrm{H}_{2}$. J. Phys. B At. Mol. Phys. 1979, 12, 3763-3773. [CrossRef]

41. Phaneuf, R.A.; Alvarez, I.; Meyer, F.W.; Crandall, D.H. Electron capture in low-energy collisions of $\mathrm{Cq}+$ and $\mathrm{Oq}+$ with $\mathrm{H}$ and $\mathrm{H}_{2}$ Phys. Rev. A 1982, 26, 1892-1906. [CrossRef]

42. Panov, M.N.; A Basalaev, A.; O Lozhkin, K. Interaction of Fully Stripped, Hydrogenlike and Heliumlike C, N, O, Ne and Ar Ions with $\mathrm{H}$ and $\mathrm{He}$ Atoms and $\mathrm{H}_{2}$ Molecules. Phys. Scr. 1983, T3, 124-130. [CrossRef]

43. Meyer, F.W.; Phaneuf, R.A.; Kim, H.J.; Hvelplund, P.; Stelson, P.H. Single-electron-capture cross sections for multiply charged O, $\mathrm{Fe}, \mathrm{Mo}, \mathrm{Ta}, \mathrm{W}$, and $\mathrm{Au}$ ions incident on $\mathrm{H}_{\text {and }} \mathrm{H}_{2}$ at intermediate velocities. Phys. Rev. A 1979, 19, 515-525. [CrossRef]

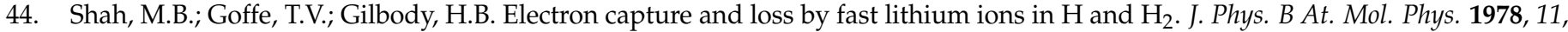
L233. [CrossRef]

45. Seim, W.; Muller, A.; Wirkner-Bott, I.; Salzborn, E. Electron capture by Lii+ $(\mathrm{i}=2,3), \mathrm{Ni}+$ and Nei+ $(\mathrm{i}=2,3,4,5) \mathrm{ions}$ from atomic hydrogen. J. Phys. B At. Mol. Phys. 1981, 14, 3475-3491. [CrossRef]

46. McCullough, R.W.; Nutt, W.L.; Gilbody, H.B. One-electron capture by slow doubly charged ions in h and $\mathrm{H}_{2}$. J. Phys. B At. Mol. Phys. 1979, 12, 4159-4169. [CrossRef]

47. Crandall, D.H.; Phaneuf, R.A.; Meyer, F.W. Electron capture by slow multicharged ions in atomic and molecular hydrogen. Phys. Rev. A 1979, 19, 504-514. [CrossRef]

48. Gardner, L.D.; Bayfield, J.E.; Koch, P.M.; Sellin, I.A.; Pegg, D.J.; Peterson, R.S.; Crandall, D.H. Electron-capture collisions at $\mathrm{keV}$ energies of boron and other multiply charged ions with atoms and molecules. II. Atomic hydrogen. Phys. Rev. A 1980, 21, 1397-1402. [CrossRef]

49. Phaneuf, R.A.; Meyer, F.W.; McKnight, R.H. Single-electron capture by multiply charged ions of carbon, nitrogen, and oxygen in atomic and molecular hydrogen. Phys. Rev. A 1978, 17, 534-545. [CrossRef]

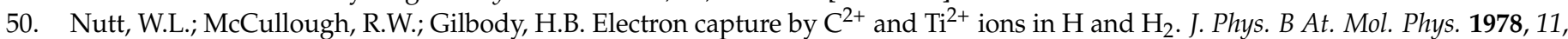
L181-L184. [CrossRef]

51. Sant'Anna, M.; Melo, W.S.; Santos, A.; Shah, M.B.; Sigaud, G.M.; Montenegro, E.C. Absolute measurements of electron capture cross sections of C3+ from atomic and molecular hydrogen. J. Phys. B At. Mol. Opt. Phys. 2000, 33, 353-364. [CrossRef]

52. Ciric, ; D.; Brazuk, A.; Dijkkamp, D.; De Heers, F.J.; Winter, H. State-selective electron capture in $\mathrm{C}^{3+}-\mathrm{H}, \mathrm{H} 2 \mathrm{collisions}(0.7-4.6 \mathrm{keV}$ $\mathrm{amu}^{-1}$ ) studied by photon spectroscopy. J. Phys. B At. Mol. Phys. 1985, 18, 3629-3639. [CrossRef]

53. McCullough, R.W.; Wilkie, F.G.; Gilbody, H.B. State-selective electron capture by slow C2+ and C3+ ions in atomic hydrogen. J. Phys. B At. Mol. Phys. 1984, 17, 1373-1382. [CrossRef]

54. Dijkkamp, D.; Ciric, D.; Vileg, E.; De Boer, A.; De Heer, F.J. Subshell-selective electron capture in collisions of C4+, N5+, O6+ with H, H2 and He. J. Phys. B At. Mol. Phys. 1985, 18, 4763-4793. [CrossRef]

55. Fritsch, W.; Lin, C.D. Atomic-basis study of electron transfer into C3+(nl) orbitals in C4++H and C4++Li collisions. J. Phys. B At. Mol. Phys. 1984, 17, 3271-3278. [CrossRef]

56. Hoekstra, R.; Beijers, J.P.M.; Schlatmann, A.R.; Morgenstern, R.; de Heer, F.J. State-selective charge transfer in slow collisions ofC4+with $\mathrm{H}$ and $\mathrm{H}_{2}$. Phys. Rev. A 1990, 41, 4800-4808. [CrossRef]

57. Stebbings, R.F.; Fite, W.L.; Hummer, D.G. Charge Transfer between Atomic Hydrogen and N+ and O+. J. Chem. Phys. 1960, 33, 1226. [CrossRef]

58. Fite, W.L.; Smith, A.C.H.; Stebbings, R.F. Charge transfer in collisions involving symmetric and asymmetric resonance. Proc. R. Soc. Lond. Ser. A Math. Phys. Sci. 1962, 268, 527-536. [CrossRef]

59. Havener, C.C.; Huq, M.S.; Krause, H.F.; Schulz, P.A.; Phaneuf, R.A. Merged-beams measurements of electron-capture cross sections for $\mathrm{O} 5++\mathrm{H}$ at electron-volt energies. Phys. Rev. A 1989, 39, 1725-1740. [CrossRef] [PubMed]

60. Huber, B.A. Electron capture by slow multiply charged Ar and Ne ions from atomic hydrogen. Eur. Phys. J. A 1981, 299, 307-309. [CrossRef] 
61. Kim, H.J.; Phaneuf, R.A.; Meyer, F.W.; Stelson, P.H. Single electron capture by multiply charged ${ }^{28}$ Si ions in atomic and molecular hydrogen. Phys. Rev. A 1978, 17, 854-858. [CrossRef]

62. Beijers, J.P.M.; Hoekstra, R.; Morgenstern, R. State-selective charge transfer in slow collisions of with H and. J. Phys. B At. Mol. Opt. Phys. 1996, 29, 1397-1408. [CrossRef]

63. Rejoub, R.; Bannister, M.E.; Havener, C.C.; Savin, D.W.; Verzani, C.J.; Wang, J.G.; Stancil, P.C. Electron capture by Ne3+ ions from atomic hydrogen. Phys. Rev. A 2004, 69, 052704. [CrossRef]

64. Havener, C.C.; Rejoub, R.; Vane, C.R.; Krause, H.F.; Savin, D.W.; Schnell, M.; Wang, J.G.; Stancil, P.C. Electron capture by Ne4+ ions from atomic hydrogen. Phys. Rev. A 2005, 71, 034702. [CrossRef]

65. Bruhns, H.; Kreckel, H.; Savin, D.W.; Seely, D.G.; Havener, C.C. Low-energy charge transfer for collisions of Si3+ with atomic hydrogen. Phys. Rev. A 2008, 77, 064702. [CrossRef]

66. Havener, C.C.; Muller, A.; Van Emmichoven, P.A.Z.; Phaneuf, R.A. Low-energy electron capture by C3+ from hydrogen using merged beams. Phys. Rev. A 1995, 51, 2982-2988. [CrossRef]

67. Mroczkowski, T.; Savin, D.W.; Rejoub, R.; Krstić, P.S.; Havener, C.C. Electron capture by Ne2+ ions from atomic hydrogen. Phys. Rev. A 2003, 68, 032721. [CrossRef]

68. Pieksma, M.; Havener, C.C. Low-energy electron capture by B4+ ions from hydrogen atoms. Phys. Rev. A 1998, 57, 1892-1894 [CrossRef]

69. Folkerts, L.; Haque, M.A.; Havener, C.C.; Shimakura, N.; Kimura, M. Low-energy electron capture by N4+ ions from H atoms: Experimental study using merged beams and theoretical analysis by molecular representation. Phys. Rev. A 1995, 51, 3685-3692 [CrossRef] [PubMed]

70. Draganić, I.N.; Seely, D.G.; Havener, C.C. Low-energy charge transfer between $\mathrm{C}^{5+}$ and atomic hydrogen. Phys. Rev. A 2011, 83, 054701. [CrossRef]

71. Cabrera-Trujillo, R.; Bruhns, H.; Savin, D.W. Acceptance-angle effects on the charge transfer and energy-loss cross sections for collisions of C4+ with atomic hydrogen. Phys. Rev. A 2020, 101, 052708. [CrossRef]

72. Greenwood, J.B.; Williams, I.D.; Smith, S.J.; Chutjian, A. Measurement of Charge Exchange and X-ray Emission Cross Sections for Solar Wind-Comet Interactions. Astrophys. J. 2000, 533, L175-L178. [CrossRef] [PubMed]

73. Janev, R.; Winter, H. State-selective electron capture in atom-highly charged ion collisions. Phys. Rep. 1985, 117, 265-387. [CrossRef]

74. Otranto, S.; Olson, R.E.; Beiersdorfer, P. X-ray emission cross sections following charge exchange by multiply charged ions of astrophysical interest. Phys. Rev. A 2006, 73, 022723. [CrossRef]

75. Andrianarijaona, V.M.; Wulf, D.; McCammon, D.; Seely, D. G.; Havener, C. C. Radiance line ratios Ly- $\beta / \mathrm{Ly}-\alpha, \mathrm{Ly}-\gamma / \mathrm{Ly}-\alpha$, Ly- $\delta /$ Ly- $\alpha$, and Ly- $\epsilon /$ Ly- $\alpha$ for soft X-ray emissions following charge exchange between $\mathrm{C}^{6+}$ and Kr. Nucl. Instrum, Methods Phys. Res. $B$ 2015, 350, 122. [CrossRef]

76. Seely, D.G.; Andrianarijaona, V.M.; Wulf, D.; Morgan, K.; McCammon, D.; Fogle, M.; Stancil, P.C.; Zhang, R.T.; Havener, C.C. Line ratios for soft-X-ray emission following charge exchange between O8+ and Kr. Phys. Rev. A 2017, 95, 052704. [CrossRef]

77. Leung, A.C.K.; Kirchner, T. Lyman line ratios in charge-exchange collisions of C6+ and O8+ ions with hydrogen and krypton atoms. Phys. Rev. A 2018, 97, 062705. [CrossRef]

78. Gu, L.; Raassen, A.J.J.; Mao, J.; de Plaa, J.; Shah, C.; Pinto, C.; Werner, N.; Simionescu, A.; Mernier, F.; Kaastra, J. X-ray spectra of the Fe-L complex. Astron. Astrophys. 2019, 627, A51. [CrossRef]

79. Gu, L.; Shah, C.; Mao, J.; Raassen, A.; De Plaa, J.; Pinto, C.; Akamatsu, H.; Werner, N.; Simionescu, A.; Mernier, F.; et al. X-ray spectra of the Fe-L complex. II. Atomic data constraints from the EBIT experiment and X-ray grating observations of Capella. Astron. Astrophys. 2020, 641, 93. [CrossRef]

80. Wargelin, B.J.; Beiersdorfer, P.; Brown, G.V. EBIT charge-exchange measurements and astrophysical applications. Can. J. Phys. 2008, 86, 151-169. [CrossRef]

81. Betancourt-Martinez, G. Benchmarking Charge Exchange Theory in the Dawning Era of Space-Born High-Resolution X-ray Spectrometers. Ph.D. Thesis, University of Maryland, College Park, MD, USA, 2017.

82. Leutenegger, M.; Beiersdorfer, P.; Betancourt-Martinez, G.L.; Brown, G.; Hell, N.; Kelley, R.L.; Kilbourne, C.A.; Magee, E.W.; Porter, F.S. Characterization of an atomic hydrogen source for charge exchange experiments. Rev. Sci. Instrum. 2016, 87, 11E516. [CrossRef] [PubMed]

83. Han, J.; Wei, L.; Wang, B.; Ren, B.; Yu, W.; Zhang, Y.; Zou, Y.; Chen, L.; Xiao, J.; Wei, B. Measurement of Absolute Single and Double Electron Capture Cross Sections for $\mathrm{O} 6+$ Ion Collisions with $\mathrm{CO}_{2}, \mathrm{CH}_{4}, \mathrm{H}_{2}$, and $\mathrm{N}_{2}$. Astrophys. J. Suppl. Ser. 2021, 253, 6 . [CrossRef]

84. Maejima, H.; Angelini, L.; Costantini, E.; Edison, M.R.; Herder, J.-W.D.; Ishisaki, Y.; Matsushita, K.; Mori, K.; Guainazzi, M.; Kelley, R.L.; et al. Concept of the X-ray Astronomy Recovery Mission. Space Telesc. Instrum. 2018 Ultrav. Gamma Ray 2018, 10699, 1069922.

85. N.; ra, K.; Barret, D.; Barcons, X.; Fabian, A.; Herder, J.W.D.; Piro, L.; Watson, M.; Adami, C.; Aird, J.; Afonso, J.M.; et al. The Hot and Energetic Universe: A White Paper presenting the science theme motivating the Athena+ mission. arXiv 2013, arXiv:1306.2307.

86. Bautista, M.; Fivet, V.; Quinet, P.; Dunn, J.P.; Gull, T.R.; Kallman, T.; Mendoza, C. Uncertainties in atomic data and their propagation through spectral models. I. Astrophys. J. 2013, 770, 15. [CrossRef] 
87. Loch, S.; Pindzola, M.; Ballance, C.; Witthoeft, M.; Foster, A.; Smith, R.; O'Mullane, M. The propagation of uncertainties in atomic data through collisional-radiative models. In Proceedings of the Eighth International Conference on Atomic and Molecular Data and Their Applications: ICAMDATA-2012, Gaithersburg, MD, USA, 30 September-4 October 2012; Volume 1545, p. 242. [CrossRef]

88. Yu, X.; Del Zanna, G.; Stenning, D.C.; Cisewski-Kehe, J.; Kashyap, V.L.; Stein, N.; Van Dyk, D.A.; Warren, H.P.; Weber, M.A. Incorporating Uncertainties in Atomic Data into the Analysis of Solar and Stellar Observations: A Case Study in Fe xiii. Astrophys. J. 2018, 866, 146. [CrossRef]

89. Foster, A.; Heuer, K. PyAtomDB: Extending the AtomDB Atomic Database to Model New Plasma Processes and Uncertainties. Atoms 2020, 8, 49. [CrossRef]

90. Morisset, C.; Luridiana, V.; García-Rojas, J.; Gómez-Llanos, V.; Bautista, M.; Mendoza, A.C. Atomic Data Assessment with PyNeb. Atoms 2020, 8, 66. [CrossRef]

91. Mehdipour, M.; Kaastra, J.; Kallman, T. Systematic comparison of photoionised plasma codes with application to spectroscopic studies of AGN in X-rays. Astron. Astrophys. 2016, 596, A65. [CrossRef] 